\title{
All Immigrants Are Not Alike: Intersectionality Matters in Views of Immigrant Groups
}

\author{
Özge Savaş ${ }^{a}$, Ronni M. Greenwood ${ }^{b}$, Benjamin T. Blankenship ${ }^{c}$, Abigail J. Stewart $^{\mathrm{d}}$, Kay Deaux ${ }^{\mathrm{e}}$
}

[a] Society, Culture \& Thought, Bennington College, Bennington, VT, USA. [b] Psychology, University of Limerick, Limerick, Ireland. [c] Psychology, fames Madison University, Harrisonburg, VA, USA. [d] Psychology and Women's and Gender Studies, University of Michigan, Ann Arbor, MI, USA. [e] CUNY Graduate Center, City University of New York, New York, NY, USA.

Journal of Social and Political Psychology, 2021, Vol. 9(1), 86-104, https://doi.org/10.5964/jspp.5575

Received: 2019-08-06 • Accepted: 2020-09-11 • Published (VoR): 2021-02-19

Handling Editor: Gülseli Baysu, Queen's University Belfast, Belfast, United Kingdom

Corresponding Author: Özge Savaş, Society, Culture \& Thought, Bennington College, One College Drive, Bennington, 05201, Vermont, USA. E-mail: ozgesavas@bennington.edu

Supplementary Materials: Materials [see Index of Supplementary Materials]

\begin{abstract}
In two studies, we investigated how intersecting social categories shape views of immigrants in the United States. In Study 1 , we analyzed 310 attributes generated by 92 participants for the category of immigrant and 30 additional immigrant groups with intersecting social categories (e.g. "undocumented immigrant") reflecting various levels of social status. Using the Meaning Extraction Method (MEM) and factor analysis to examine shared meanings, we identified five factors; further comparative analyses of immigrant groups focused on the first two factors (Vulnerable vs. Hardworking, Drain vs. Asset). The importance of legal status for judgments on these two factors was evident in comparisons of the generic immigrant with four specific legal intersections. An examination of all 31 groups of immigrants showed that higher status groups were perceived as Hardworking (less Vulnerable) and high national Assets (low Drain), while lower status groups varied in Vulnerability perceptions but were generally thought to be Drains on the nation rather than Assets. In Study 2, 270 participants evaluated intersectional immigrant social categories that differed in combinations of higher status (privileged) and lower status (marginalized) social group memberships, using scales based on the terms identified by the factors in Study 1. Participants rated immigrant groups with two privileged statuses as less vulnerable and more likely to be an asset to the nation than immigrant groups with two marginalized or mixed statuses. The utility of a bottom-up intersectional approach to assess stereotype content of immigrant groups is discussed.
\end{abstract}

\section{Keywords}

immigration, intersectionality, meaning extraction method, immigrant stereotypes

\section{Non-Technical Summary}

\section{Background}

The meanings attached to who an immigrant is vary across countries and over time, due to each country's unique history of migration, immigration policies, and racial, ethnic and religious tensions. Immigrants within a given country do not make up a single group; therefore, citizens' understandings of immigrants depend on immigrants' identities such as race, ethnicity, gender, religion. 


\section{Why was this study done?}

The existing understanding of immigrant stereotypes is based on researcher-generated descriptions. We do not know enough about how people in the U.S. attach different meanings to different groups with various levels of privilege and marginalization. For example, how different are people's ideas about undocumented and documented immigrants? Or how different are their ideas about a British immigrant from a Mexican immigrant?

\section{What did the researchers do and find?}

In Study 1, participants generated one-word descriptions of 31 different immigrant groups. We analyzed this participant generated word pool, and found two meaningful factors that described people's ideas about immigrants. U.S. citizens were likely to evaluate immigrants on a continuum of (1) vulnerable to hard-working, and (2) national drain to asset.

In Study 2, we used the participant-generated words to assess how people judge immigrants with different levels of privilege. People perceived higher status groups as hard-working (less vulnerable) and assets to the nation, and lower status groups as drains. Immigrant groups with two privileged statuses (e.g., documented Canadian immigrant) were viewed as less vulnerable and more of an asset to the nation than immigrant groups with two marginalized statuses (e.g., undocumented Mexican immigrant) or mixed statuses (e.g. documented Mexican immigrant).

\section{What do these findings mean?}

Not all immigrants are alike in the eyes of U.S. citizens. The immigrant groups that were ascribed positive characteristics most often belonged to privileged groups, marked by their use of English, proximity to Whiteness, and/or higher occupational status. These studies show us that immigrant groups are variously accepted into U.S. society, based on their ethnic, racial and religious resemblances to the dominant majority, as well as by the opportunities and challenges arising from their educational and professional statuses.

In 2017, more than 250 million people lived in a country other than their country of birth (United Nations, 2017). As the migration flows increased, the U.S. government attempted to reduce immigration, barred refugees, and criminalized border crossers. Against the backdrop of these policy changes and rhetoric, we aim to understand how ordinary U.S. citizens view immigrants. Is a single image or stereotype applied to all immigrants, whatever their country of origin or other defining features? Or do intersections of immigrants' social categories, such as country of origin, legality, and gender create more complicated images?

\section{Changing Patterns and Policies in U.S. Immigration}

Immigrant groups are integrated into receiving societies, based on their ethnic, racial and religious resemblances to the dominant majority, as well as by the affordances and challenges arising from their educational and professional statuses (Alba \& Foner, 2015). Dominant majority group members' attitudes vary over time and across contexts, shaping and shaped by policies, and immigrant flows (Deaux, 2006). Thus, every nation-state has a unique history of relating to various immigrant groups. In the U.S., the 1965 immigration policy eliminated previous ethnoracial exclusions and tipped the balance of immigrants toward Caribbean, Latin American, Asian, and more recently African heritage (Alba \& Foner, 2015). The new immigrant flows accelerated the debates about which immigrant groups are more or less welcome, and legality, rarely discussed in earlier eras, has taken center stage (Cisneros, 2015; Ngai, 2004). This differential treatment of immigrants over the course of history, in the U.S. and elsewhere, results in some immigrant groups being seen as more desirable than others, and points to the value of an intersectional approach to thinking about dominant majority's views of immigrants.

\section{An Intersectional Perspective on Immigrant Groups}

Theories of intersectionality (Crenshaw, 1991; Cole, 2009; Collins, 2015) suggest that combinations of categories define a person's status in social structures, have emergent meanings that differ from their constituent parts, and influence 
impressions and behaviors. Collins (2015) stated, “... race, class, gender, sexuality, ethnicity, nation, ability, and age operate not as unitary, mutually exclusive entities, but rather as reciprocally constructing phenomena." (p. 41). Social structures include status distinctions or social positions on more than one dimension. An individual's social experience (in terms of dominance or oppression, discrimination and opportunity) results from the combination of these statuses and positions. Intersectionality has been remarkably effective in illuminating experiences of black women in contrast to experiences of black men and white women (e.g., Bowleg, 2008; Settles, 2006).

Intersectionality theories emphasize the interrelatedness of different axes of oppression, and how they are mutually constitutive. Thus, precisely what "gender" means is constituted in part through race and class, just as what class and race mean are constituted in part through each other and through gender. More narrowly, intersectionality theory makes clear that "gender" cannot really be defined without other referents, because, for example, the definition of masculinity for white middle-class men (e.g., as decisive, competent, and protective) is different from that of black middle-class men (e.g., as strong and dangerous) or white working-class men (e.g., as hard-working and angry). In this example, masculinity is constituted through race and class. More generally, the experience of gender is always influenced by all aspects of an individual's social position (e.g., Bowleg, 2008; Ortner, 2003). For our purposes the question was: how is the immigrant category differentially perceived as a function of other axes of social status and identity?

Finally, intersectionality is always concerned with issues of inequality. Hierarchical distinctions are implicated in axes of power, indexing inequities for different groups. Because intersectional approaches focus on individuals' precise experiences at these intersections, they can identify aspects of stigma, prejudice, discrimination and inequitable outcomes for particular groups (Cole, 2009; Purdie-Vaughns \& Eibach, 2008; Rosenthal, 2016). We used an intersectional approach to identify the ways immigrants-defined by one axis of power-are differentiated along other dimensions, creating distinct intersectionally-defined groups.

The image of an immigrant (vs. someone native-born) is generally associated with lower power and status in many societies, but immigrants have additional social positions that affect their status. These include reasons for migration (voluntary vs. forced) and legality (documented vs. undocumented), as well as membership in social categories such as ethnicity, religion, gender, and sexual orientation. Country of origin is also often a marker of religion and social status (Koch et al., 2016). These intersections are situated historically, politically, and socially within a hierarchy of power relations between groups. Differences in the content of stereotypes about, and attitudes toward, specific groups result, we suggest, not only from being part of the category "immigrant" but also from the intersections of immigrants' other high (privileged) and low (marginalized) status category memberships.

\section{Content of Immigrant Stereotypes}

Psychological research on group stereotypes dates from the classical work of Katz and Braly (1933). Subsequent use of both free-response and checklist methods yielded evidence of multiple dimensions reflecting not only traits, but also physical characteristics and behaviors (e.g., Madon, 1997; Niemann et al., 1994). The Stereotype Content Model (e.g., Fiske et al., 2002) proposed that warmth and competence are two fundamental dimensions of perceived group differences in traits. In a study of 25 immigrant groups that varied in ethnic/national origin, legality, generation, and occupational category (Fiske \& Lee, 2012), some immigrant groups, such as Indians and third-generation immigrants (nationality unspecified), were rated highly on both competence and warmth, similar to ratings of an "American college student." Other immigrants, such as undocumented, Mexican, African, and South American, were rated low on both competence and warmth. These researchers concluded that nationality was the most important influence on people's assessments of competence and warmth. Using an alternative set of dimensions, Zou and Cheryan (2017) demonstrated that ratings of racial-ethnic minority groups vary on dimensions of perceived inferiority and cultural foreignness.

Although these classification systems have demonstrated utility, their predetermined dimensions may not fully capture the meanings associated with immigrants. Recent research has shown advantages of inductive, respondent-driven approaches and of identifying more than two dimensions of stereotype content. For example, using a data-driven approach, Koch and colleagues (2016) identified two somewhat different dimensions (agency/socioeconomic success, and conservative-progressive beliefs), along with a third "emergent" dimension (communion), in a study of stereotype 
content generated for many groups. Like Echabe and Castro (1996), we assume that stereotypes of immigrants are responsive to contextual variation and change, such as immigrants' country of origin and the social policies that determine which immigrant groups are more or less welcome during any given period. Research suggests that legal status, a particularly contentious aspect of current immigration debates, is a powerful predictor of attitudes and stereotypes (Mukherjee et al., 2012; Murray \& Marx, 2013; Verkuyten et al., 2018). Other important immigrant characteristics that shape attitudes and stereotypes include gender, race, occupation, and education (e.g., Timberlake \& Williams, 2012). All of these indicators of social status and relative privilege in society may influence perceptions of different immigrant groups. Thus, in Study 1, we use an intersectional approach to inductively explore the contemporary stereotype content of different immigrant groups in the United States.

\section{Views of Immigrants With Differing Intersecting Identities}

Attributions of particular characteristics that coalesce into stereotypes reflect attitudes about immigrants, which are often ambivalent and variable by time and context (Ceobanu \& Escandell, 2010). One source of negative attitudes is the realistic and symbolic threats that newcomers evoke (Curşeu et al., 2007; Stephan et al., 2005). Sources of symbolic threat include immigrants' legal status, English language fluency, occupational skills, and workforce intentions (Hainmueller \& Hopkins, 2014; Schildkraut, 2011). Qualities perceived as attractive-such as advanced education, professional credentials and English competence-may evoke positive attitudes. Differences among these legal markers, such as whether a person arrived as a refugee, asylum-seeker, undocumented, or documented, may create different images of and attitudes toward the immigrant group (Kotzur et al., 2017; Verkuyten et al., 2018). However, neither legality nor ethnicity independently shapes attitudes toward immigrants. Hartman and colleagues (2014) found stronger negative attitudes toward Hispanic vs. White immigrants who work off the books or are undocumented illustrating the utility of an intersectional approach to immigrant stereotype content.

\section{Overview of the Two Studies}

Our first goal was to investigate immigrant stereotype content inductively. We applied Chung and Pennebaker's (2008) Meaning Extraction Method (MEM) to data produced by participants who were asked to give descriptors of various immigrant groups (Study 1). Research with the MEM has shown how language use can be analyzed to extract information about people's thoughts, values, emotions and motives, as well as social processes and mental health (Boyd, 2017). MEM is equally appropriate for "bottom-up" investigations of stereotype content (as articulated in language) associated with particular social groups. This bottom-up approach allowed us to examine differences in stereotypes of particular groups of immigrants without constraining the structure or content of those beliefs.

In Study 1 we asked participants to attribute characteristics to an uninflected "immigrant" category and to 30 groups of immigrants with an additional intersecting category membership (e.g., female immigrant), allowing us to compare these groups with each other as well as to judgments of the generic immigrant category. Participant-generated characteristics formed the data set for MEM analysis, yielding a set of factors/dimensions that best represented the overall attribute set. We then examined whether groups of immigrants were perceived differently in terms of the obtained dimensions. Based on previous findings of the importance of legal status in contemporary immigration debates, we assessed patterns of stereotype content for immigrants defined by legality (documented, undocumented, asylum-seeker, and refugee). We then looked at immigrant intersections with other social categories (e.g., gender, sexual orientation, national origin, and religion) that reflect higher vs. lower status in U.S. society. For example, in the U.S., immigrants from predominantly White and Christian nations (e.g., Canada) have higher social status; immigrants from predominantly non-White countries or with non-Christian religious affiliations (e.g., Hindu) have a status disadvantage (e.g., Timberlake et al., 2015). Similarly, English-speaking, professional and skilled immigrants have higher social statuses compared with unskilled workers (Krieger et al., 1997). Non-English-speaking immigrants have lower status on the basis of their perceived foreignness (e.g., Timberlake et al., 2015).

In Study 2, we examine immigrant stereotype content as a function of the immigrants' membership in intersecting social groups, defined specifically by two social categories other than immigrant, each of which reflected higher or lower social status in contemporary U.S. society. Each immigrant group was defined by either two privileged, two 
marginalized, or mixed (one privileged, one marginalized) social categories. We expected that immigrants belonging only to privileged social categories would be judged most positively and that immigrants belonging only to marginalized social categories would be judged most negatively. We anticipated that membership in one privileged social category would limit the negative impact of low status in another, while membership in a marginalized social category would limit the benefit of the higher status category membership (Settles \& Buchanan, 2014) in terms of stereotype content, yielding a mid-range judgment. Specifically, our research questions were:

In Study 1:

(i) What are the features of immigrant stereotype content in the United States?

(ii) Does this content differ for immigrant groups that vary in other intersecting category memberships? Specifically, (a) do variations in legality alter the general stereotype of immigrant? and (b) how do other intersecting categories, such as nationality/ethnicity, gender, sexual orientation, language, religion, occupational status, and family role influence the stereotype content of immigrant?

In Study 2:

(iii) How does the status or privilege associated with the various intersecting categories affect views of the immigrant group? Specifically, are groups evaluated differently depending on whether the intersecting categories are all privileged, all marginalized, or a combination of the two?

\section{Study 1: Stereotype Content of Immigrants in the United States}

Our goal was to understand the diversity of immigrant stereotype content in the U.S. through induction. Participants generated attributes for immigrant groups with various social statuses, including a generic immigrant category, and 30 groups in which "immigrant" was further identified by its intersection with another social/demographic category. These categories covered the domains of legal status, nationality/region, gender, sexual orientation, language usage, religion, skill level, and family role. We expected that intersections of high and low status social categories would yield different patterns of trait attribution to the varying immigrant groups.

\section{Method}

\section{Participants and Procedure}

We followed the U.S. Federal Policy for the Protection of Human Subjects and obtained approval for our study procedures from the Institutional Review Board. Every participant provided informed consent prior to completing the survey. The survey was distributed in 2017 to an online sample of Amazon Mechanical Turk (MTurk) workers living in the U.S. and not concentrated in a particular region. A total of 121 individuals responded. Participants were paid $\$ 1.50$ for completing the survey ( $\$ 0.10$ per minute). We dropped 29 participants who did not finish the survey, resulting in a final sample of 92 (see Section A1 of the Supplementary Materials for additional information on the sample).

\section{Materials and Analytical Strategy}

The unit of analysis was the terms generated to describe immigrant groups; that is, every descriptor participants spontaneously generated for each immigrant group label was included in a combined word pool of 2844 words, with an average of 91 different terms for each category (range from 76 to 111) (see Section A2 of the Supplementary Materials for more on the decisions about data cleaning and analyses). We used the Meaning Extraction Helper (MEH) to assess the co-occurrence of words across different categories in the word pool. MEH is a computerized text analytic tool that allows researchers to analyze textual data-in this case words describing immigrants-(Chung \& Pennebaker, 2008). The MEH output was a matrix of the participant-generated terms across one axis and each immigrant category on the other axis. The output matrix contained 1's (present) and 0's (absent) to indicate whether or not each of the participant-generated terms $(N=310)$ was used by any of the participants to describe each immigrant category $(N=31)$. 
Use of the binary data is recommended by Pennebaker and his colleagues for the kind of factor analysis conducted here (Boyd \& Pennebaker, 2015; Chung \& Pennebaker, 2008). We first used this matrix to factor analyze the terms obtained from participants and to assess co-occurrence of words that reflected some underlying idea or dimension. We then compared groups differing in legal status on the two primary factors. Finally, we displayed positions of all 31 groups on those two factors.

\section{Results}

\section{Most Frequent Terms Used in Describing Immigrants}

Overall, participants mentioned many more pleasant attributes than unpleasant ones. Notably, "hard-working" is by far the most common attribute associated with immigrants, mentioned almost three times as often as the next most frequent term (see Section A3 of the Supplementary Materials for more information of the most frequent terms).

\section{Factor Analysis}

We followed procedures previously used with the MEM approach (Boyd \& Pennebaker, 2015), using a Principal Components Analysis (PCA) extraction method with varimax rotation (Abdi \& Williams, 2010; see Niitsuma \& Okada, 2005 on the use of PCA for categorical variables). We examined all rotated factor solutions from four to 10 factors and concluded that the five-factor solution offered the most parsimonious and interpretable structure. Items were included if they had loadings above .4 and did not cross-load above .3 on any other factor. The first factor (named Vulnerable vs. Hardworking) explained $8 \%$ of the total variance; the second (National Drain vs. Asset) explained an additional 6\%; the third (Worthy), fourth (Communal vs. Individual) and fifth factors (Sociable) each added approximately 5\%. The total variance explained by the five-factor solution was $29 \%$. Although this percent of variance may seem low for social science survey and personality data, it is high for analyses of participant-generated language. Previous studies with 6 or 7 factors accounted for a total of $14-15 \%$ of the variance in 88-132 terms from 134 to 560 participants or 1165 essays (see e.g., Chung \& Pennebaker, 2008; Ramírez-Esparza et al., 2012).

The first factor, labelled Vulnerable vs. Hardworking, included the terms fearful, fragile, needy, desperate, scared, sad, weak, and humble at one end, and hardworking at the other. Confirmatory reliability analysis $(\alpha=.85)$ indicated excellent reliability (see Table 1 for factor loadings).

Table 1

Factor Loadings for Exploratory Factor Analysis With Varimax Rotation

\begin{tabular}{lc}
\hline Factor content & Factor loadings \\
\hline Factor 1: Vulnerable vs. Hardworking & \\
fearful & .83 \\
fragile & .76 \\
needy & .75 \\
desperate & .70 \\
scared & .68 \\
sad & .65 \\
weak & .65 \\
humble & .58 \\
hardworking & -.43 \\
\hline
\end{tabular}

$\begin{array}{lc}\text { Factor 2: National Drain vs. Asset } & \\ \text { lowerclass } & .71 \\ \text { educated } & -.64 \\ \text { criminal } & .61 \\ \text { funny } & -.56 \\ \text { not wanted } & .54 \\ \text { welfare seeker } & .54\end{array}$




\section{Factor content}

Factor loadings

$\begin{array}{lc}\text { similar } & -.50 \\ \text { dumb } & .48 \\ \text { poor } & .47 \\ \text { ignorant } & .45 \\ \text { lazy } & .45 \\ \text { annoying } & .44 \\ \text { unskilled } & .43 \\ \text { smart } & -.43 \\ \text { illegal } & .42 \\ \text { assimilates } & -.42 \\ \text { skilled } & -.42 \\ \text { dangerous } & .42 \\ \text { untrustworthy } & .42 \\ \text { has kids } & .41\end{array}$

\section{Factor 3: Worthy}

safe

outgoing

$-.62$

$-.56$

devoted

$-.52$

excited

$-.52$

faithful

$-.49$

moral

$-.49$

creative

$-.45$

kind

$-.43$

religious

$-.41$

\section{Factor 4: Communal vs. Individual}

$\begin{array}{lr}\text { eager } & -.57 \\ \text { reliable } & -.55 \\ \text { helpful } & -.54 \\ \text { able } & .53 \\ \text { capable } & .52 \\ \text { bilingual } & -.48 \\ \text { different } & .44 \\ \text { loud } & .44 \\ \text { masculine } & .43 \\ \text { strict } & .43 \\ \text { mean } & .42 \\ \text { compassionate } & -.41 \\ \text { dark-hair } & .40\end{array}$

\section{Factor 5: Sociable}

$\begin{array}{lc}\text { accented } & .62 \\ \text { family(-oriented) } & .50 \\ \text { curious } & .47 \\ \text { giving } & .44 \\ \text { selfish } & -.42 \\ \text { interest(ed) } & .40 \\ \text { alcohol drinker } & .40\end{array}$

Note. Terms are included in this table if their frequency was above 5 and they loaded on a factor by .40 or above. Double-loading terms are not included here or in the factor calculations. Words with minus signs (negative loadings) were subtracted in calculating factor scores. In some cases, participants provided racial or ethnic markers that defined groups or categories rather than traits. Terms that were synonyms or near-synonyms for any given category were excluded from calculation of factors. More generally, terms that were not a trait, characteristic, or attribute were excluded from the factor structure. 
The second factor, labelled National Drain versus National Asset, was also bipolar, including the terms lower class, criminal, not wanted, welfare seeker, dumb, poor, ignorant, lazy, annoying, unskilled, illegal, dangerous, untrustworthy, and has kids loading at one end; and educated, funny, similar, smart, assimilates, and skilled loading at the other. Confirmatory reliability analysis $(\alpha=.86)$ also indicated excellent reliability.

The third unipolar factor, labelled Worthy, included the descriptions safe, outgoing, devoted, excited, faithful, moral, creative, kind, and religious. Confirmatory reliability analysis $(\alpha=.72)$ indicated somewhat lower reliability.

The fourth factor was bipolar and more difficult to interpret than the first three. We labelled the poles Communal versus Individual. It included the terms eager, reliable, helpful, bilingual, and compassionate with negative loadings; and the terms able, capable, different, loud, masculine, strict, mean, and dark hair with positive loadings. Confirmatory reliability analysis yielded an alpha of .78 .

The fifth and final factor was also difficult to interpret and had the lowest reliability $(\alpha=.65)$. It included the terms accented, family-oriented, curious, giving, interested, and alcohol-drinker, loading positively; and selfish loading negatively. We labelled it Sociable to encompass the other-orientation of terms like family-oriented and giving (and the negatively loaded selfish) as well as the sense that alcohol-drinker in the context of these attributes implied some sociability.

In our view, the first three factors were easy to interpret, while the last two were quite difficult. However, only the first two factors showed excellent reliability. We confirmed this by performing a split-half reliability analysis (see Section A4 of the Supplementary Materials). Finally, in preliminary analyses, only the first two factors differentiated among the immigration legal statuses studied in the next section. For these reasons, all subsequent analyses are limited to the first two factors.

\section{Immigration Status and Patterns of Impressions by Legal Status}

We used the factors as a basis for comparison of the various legal categories with the generic immigrant category. Next, we produced scales for each factor. We calculated total scores for each factor by summing the frequency of terms in every factor (with negatively loading terms subtracted from the total) across participants for each of the 31 groups. We standardized the total scores for each factor $(M=50, S D=10)$, using all 31 categories. Given the small number of people $(N=20)$ who provided terms for each immigrant group, we restricted our analysis to visual inspection and description of the pattern of scores rather than employing potentially spurious statistical tests of differences.

The generic category "immigrant" (see Figure 1) serves as one reference point for considering the four more specified groups. The other reference point is the 0 point (the mean). 'Immigrant' was about .5 standard deviation above the mean on Vulnerable vs. Hardworking (toward the Vulnerable end) and nearly 1.0 standard deviation below the mean on National Drain vs. Asset (toward the Drain end). Undocumented immigrant is the category that most closely matches the patterns of the generic immigrant, differing primarily in being described as a greater Drain than the generic immigrant. In contrast, documented immigrants were rated most favorably distinct (more Hardworking and more of an Asset) from the generic immigrant and the other three groups. Descriptions of asylum-seekers were 2.0 standard deviations above the mean on Vulnerable vs. Hardworking (more Vulnerable) and 1.0 standard deviation below the mean on National Drain vs. Asset (more of a Drain). Refugees were described similarly to asylum-seekers, but as even more Vulnerable. In sum, this display gives us new insights into the ways in which the particularities of legality shapes images of immigrants. 


\section{Figure 1}

Standardized Factor Scores by Immigrant Groups

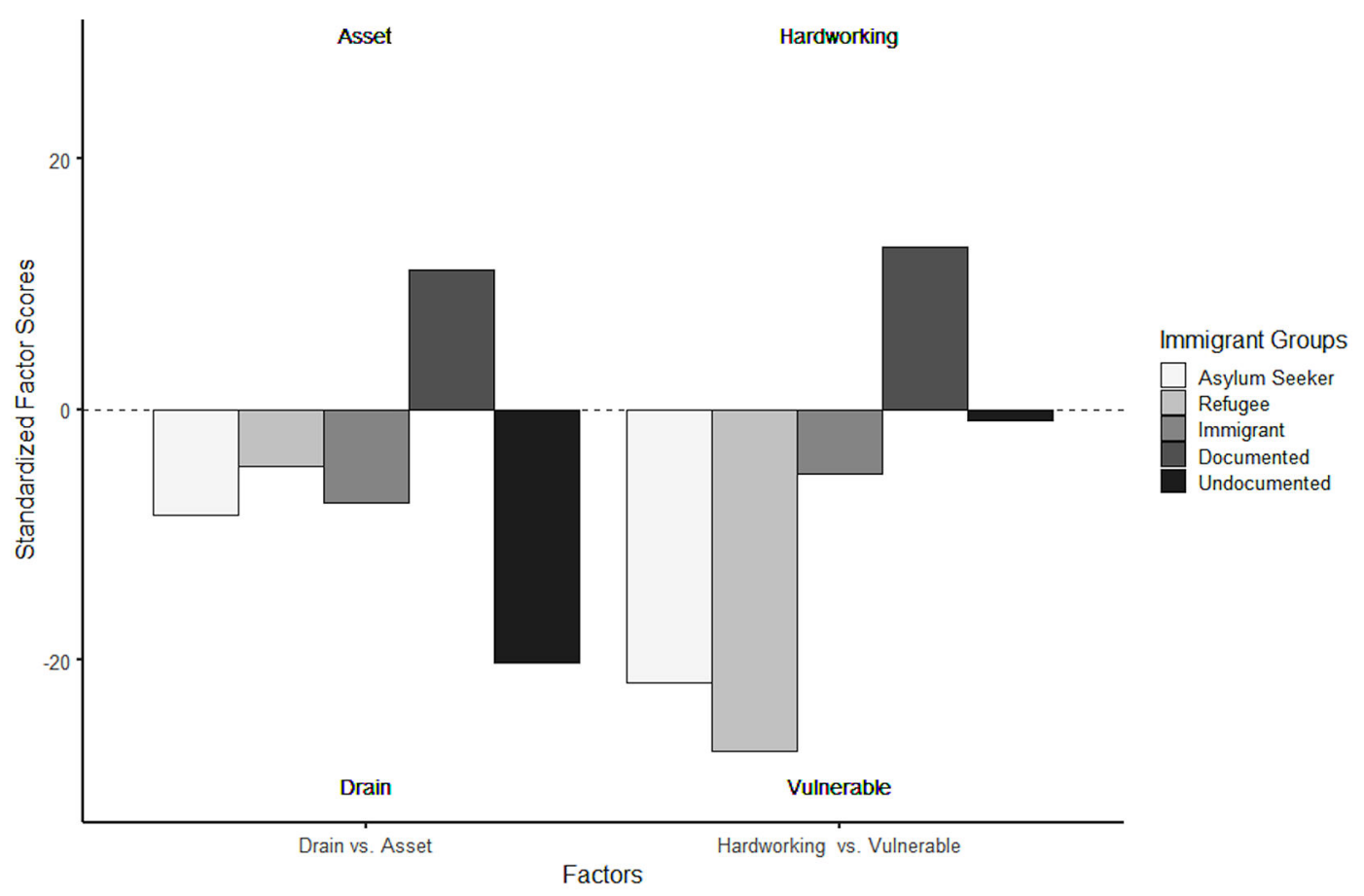

Note. In order to more effectively demonstrate the relative differences between the 5 main groups of interest, the original scores were re-centered around a score of 0 (the original mean was 50), allowing for the positive and negative scores reflected in this figure. Original scores reflected a mean of 50 and a standard deviation of 10, and can be viewed in their original scale in Figure 2.

\section{Impressions of Immigrant Groups on Two Primary Factors}

Next, we considered all 31 groups rated by participants. We limited analysis to the first two factors, which accounted for the most variance and elicited greatest variability in comparisons of legal categories. These two dimensions defined somewhat related themes indicating relative strength or weakness of the group, with the first dimension (Vulnerable vs. Hardworking) emphasizing the immigrant group's relative need for assistance at the low end and the second (National Drain vs. Asset) emphasizing the group's relative demand on societal resources at the low end. Accordingly, we created a two-dimensional space for descriptive analysis of the position of all 31 groups. These results, shown in Figure 2, illustrate how particular immigrant groups are viewed similarly to or differently from others. We can also assess whether relative status positions seem to underlie placement in terms of these two dimensions.

Visually, the plot in Figure 2 suggests that immigrant groups are differentiated most clearly in terms of being seen as a Drain or Asset. Groups within the upper right quadrant, described as Assets to the nation and more Hardworking than Vulnerable, included British, Canadian, German, South-Asian, English-speaking, professional, skilled, and documented immigrants. Among these, the least Vulnerable/most Hardworking were the documented and skilled immigrants. Groups in the lower right quadrant were described as Drains on national resources, but not particularly Hardworking or Vulnerable, with unskilled immigrants seen as the most likely to be Drains. Groups seen as less Vulnerable/more Hardworking, but still a likely Drain, included Irish, Polish, Mexican, and straight immigrants. In the lower left quadrant are groups described as more of a Drain than an Asset, with some variations in perceived Vulnerable vs. Hardworking. Syrian immigrants, refugees, and asylum-seekers were seen as the most Vulnerable; other groups considered somewhat less Vulnerable but still a Drain included Nigerians, Muslims, Arabs, parents, and the generic immigrant. The final quadrant (high Asset, high Vulnerability) included no groups scoring high on both dimensions: Hindu and child immigrants were both seen as essentially neutral on the dimension of Drain vs. Asset with Hindus Hardworking and low in Vulnerability and children very high in Vulnerability. 


\section{Figure 2}

Plot of "National Drain vs. Asset" Factor and "Vulnerable vs. Hardworking" Factor for All Groups

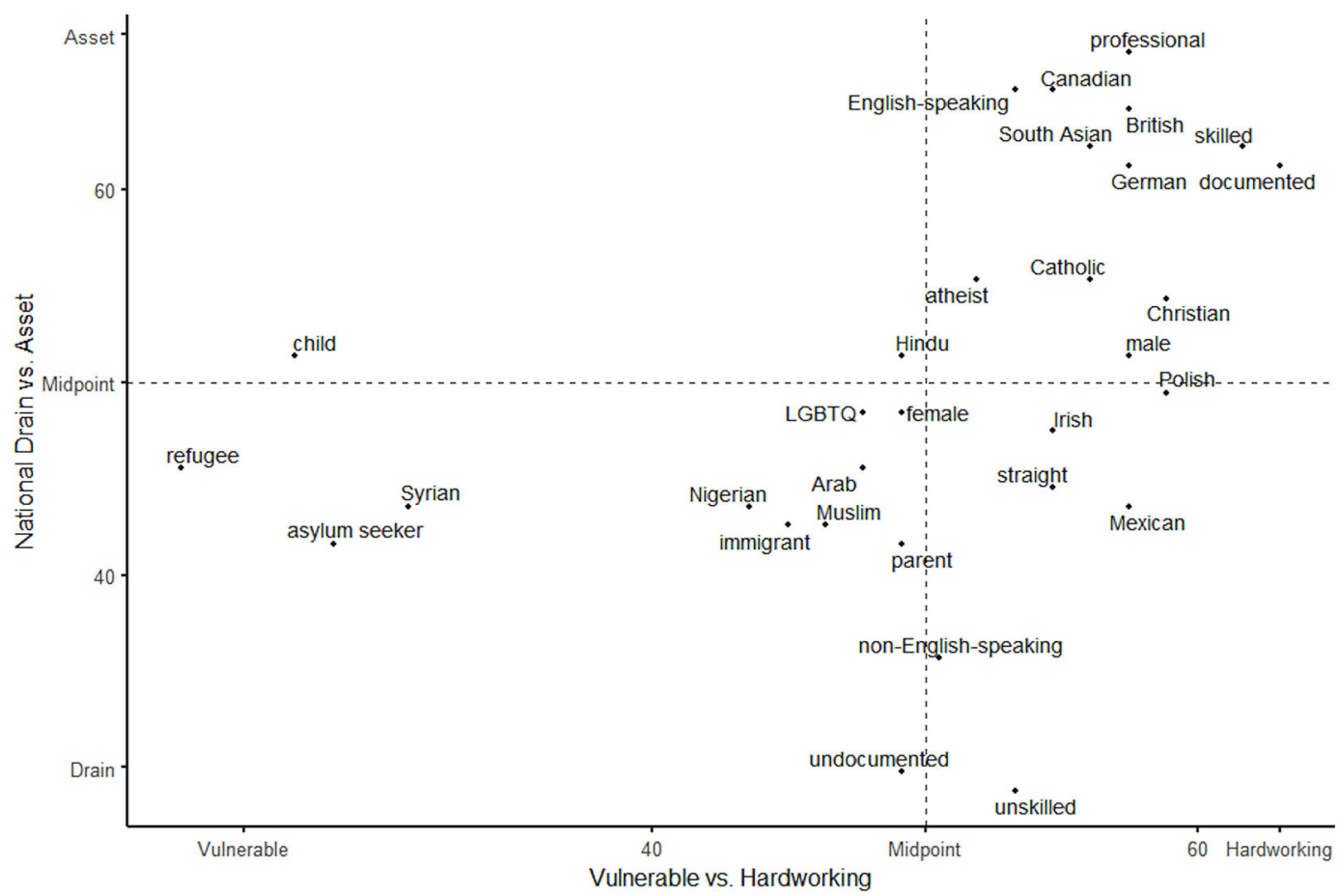

Note. Prior to figure creation, raw scores were standardized across all groups, centering to a mean at 50 and a standard deviation of 10.

These results confirm our expectation that intersecting power relations that define a given group's social status are important. Specifically, immigrant groups with a higher status intersecting category in terms of work (professional or skilled), legality (documented), or nation (also related to race: White and Asian) were all located in the most favorable quadrant, seen as Assets and Hardworking. Groups with a lower status intersecting category were distributed in quadrants defined as a Drain but varying in perceived Vulnerability (e.g., both Mexicans and Nigerians were both perceived as a Drain, but Mexicans were considered more Hardworking). The most Vulnerable among these were Syrian immigrants, refugees and asylum-seekers.

\section{Discussion}

Testing the hypothesis that not all immigrants are alike in the public imagination and that stereotype content is variable and context-dependent, we assessed beliefs about 31 immigrant groups. We identified five dimensions of immigrant stereotype content. The two strongest factors were retained for subsequent analysis: Vulnerable vs. Hardworking and Drain vs. Asset. The remaining three factors are Worthy, Communal vs. Individual and Sociable. Altogether factors include a mix of pleasant and unpleasant attributes.

Four categories associated with legality (documented, undocumented, asylum-seeker, and refugee) were compared to the generic immigrant. Generic immigrants were viewed most like undocumented immigrants, differing primarily in being described more as drains. In contrast, images of documented immigrants were the most positive of all groups and differentiated from the generic immigrant, even though the majority of immigrants to the U.S. are documented. Refugees and asylum-seekers were rated as most vulnerable. These findings highlight the influence of socio-historical context on construction of categories, and the generic immigrant's dependence on other categories for meaning. 
Finally, when all immigrant groups were plotted on the first two factors, immigrants with higher status (i.e., British, Canadian, German, South-Asian, English-speaking, professional, skilled, and documented) were viewed most favorably, as hardworking assets. Groups viewed as drains rather than assets were generally low-status, marginalized groups (i.e., Mexican, Arab, Muslim, Nigerian, Syrian, non-English-speaking, unskilled, undocumented, refugee, asylum-seeker). Within this group, however, there was some variation in perceived vulnerability (e.g., Mexicans viewed as more hardworking; Syrians and refugees seen as more vulnerable).

Our findings support the utility of assessing immigrant stereotypes across a wide range of social categories intersecting with immigrant and attest to the value of an inductive approach to determining stereotype content. The characteristics that were generated by our participants and the bi-directional nature of the two most dominant factors (i.e. vulnerable vs. hardworking, and drain vs. asset) seem to mirror the contemporary tensions in discussions about immigrants, and therefore are fairly more specific than researcher-generated stereotypes such as competence and warmth (Fiske et al., 2002). The Vulnerable vs. Hardworking dimension includes at least one term that overlaps with Fiske et al.'s Competence dimension, and Drain vs. Asset includes several, but there are many other terms in each factor that are not captured by the SCM. In our view, this shows the value of assessing stereotypes that are particular to the immigrants inductively.

\section{Study 2: Immigrant Stereotype Content and Response to Different Immigrant Groups}

For this study we developed closed-ended measures of the two dimensions identified in Study 1. Then we tested the hypothesis that people's judgments of immigrant groups representing various intersections are influenced by the status and privilege of those categorical memberships. We developed a set of scalar items based on Study 1 and directly assessed participants' views of immigrants. This allowed us to test whether these scales could effectively differentiate judgments of intersectionally-defined immigrant groups different from those examined in Study 1. We defined three patterns of intersectionality: immigrants with two privileged social category memberships, immigrants with two marginalized category memberships, and immigrants with mixed (one marginalized and one privileged) category membership. We predicted that immigrants who were members of two privileged categories would be rated most favorably on Asset and Hardworking; that groups with two marginalized category memberships would be rated lowest on Asset and Hardworking (and less Vulnerable); and that groups with mixed category memberships would receive intermediate ratings on both dimensions. To develop these measures and test these hypotheses we collected data from a second sample of respondents.

\section{Method}

\section{Participants and Procedures}

We obtained approval for study procedures from the Institutional Review Board (IRB). Our survey was distributed online in December 2018 to a new sample of MTurk workers (see Section B1 of the Supplementary Materials for sample characteristics). Participants were paid $\$ 2.50$ for completing the survey ( $\$ 0.10$ per minute). Participants responded to items about immigrant groups identified by either two privileged categories (e.g., Documented Canadian immigrant), two marginalized categories (e.g., Undocumented Mexican immigrant), or one privileged and one marginalized (mixed) category (e.g., Documented Mexican immigrant). These combinations allowed us to assess whether stereotypic trait judgments of intersectionally-defined immigrants were influenced by the status characteristics of their categories. Each participant was presented with a randomly selected set of four immigrant groups out of a total set of 36; each immigrant group was rated by 30 participants. The random sets of immigrant categories included a combination of two or three immigrant categories defined by privileged, marginalized, or mixed statuses (see Section B2 of the Supplementary Materials for details). 


\section{Materials}

Primary dimensions of immigrant impressions - To assess impressions of these intersectional immigrant groups, we created two scales based on the items generated by participants in Study 1 that loaded on Factors 1 (Vulnerable vs. Hardworking) and 2 (National Drain vs. Asset). We eliminated words with the same meaning (e.g., scared, and fearful) and chose words with the highest overall frequency. Participants rated each item on the two scales for each of the groups they were given, from 1 (not at all) to 5 (extremely), in terms of how common it is for members of a given group to have this attribute. Items from the two scales were interspersed and randomized in the survey.

Vulnerable vs. Hardworking. Vulnerable vs. Hardworking was assessed with five items: needy, desperate, scared, weak, and hardworking (the former four reverse coded); it had good reliability $(\alpha=.81)$.

National drain vs. asset. Drain vs. Asset was assessed with 10 items: educated, similar to Americans, smart, assimilates, criminal, poor, lazy, welfare-seeker, untrustworthy, dangerous (the latter six were reverse coded). This scale had excellent reliability $(\alpha=.88)$ (see Section B3 of the Supplementary Materials for further information on the scales).

Additional measures - Warmth and competence. We used three additional measures as controls to assess the robustness of the two dimensions identified in Study One. We noted that the Vulnerable vs. Hardworking factor included one item (hardworking) that could be interpreted as a sign of strength and competence on the one hand, and perceptions of weakness and vulnerability on the other hand. To determine whether basic dimensions of warmth and competence might influence judgments on our two factors, we included separate scales assessing warmth and competence ratings, as defined by the Stereotype Content Model (Fiske et al., 2002). Our Warmth measure included four items from the SCM warmth scale: good natured, warm, tolerant, sincere. The Warmth scale had excellent reliability $(\alpha=.88)$. Our Competence measure included five items from the SCM competence scale: competent, confident, independent, competitive, intelligent. The Competence scale also had excellent reliability $(\alpha=.84)$. Participants rated each item on the two scales for each of the four groups they were given, from 1 (not at all) to 5 (extremely), in terms of how common it is for members of a given group to have this attribute.

Threat. Our Drain vs. Asset factor included some items (e.g., dangerous, criminal) that could be interpreted as closely related to perceptions of threat. To determine whether our scales were independent of measures of threat, we created six items, three for each, for assessing participants' perception of immigrant groups as posing symbolic threat and realistic threat. An example item for realistic threat is "[... immigrants] take jobs from qualified American people."; and an example item for symbolic threat is "[... immigrants] threaten American way of life." Participants rated each item on a scale from 1 (strongly disagree) to 5 (strongly agree) for each group. The scale had excellent reliability $(\alpha=.87)$.

\section{Results}

\section{Assessing Views of Three Types of Intersecting Immigrant Groups}

The correlation between the Vulnerable vs. Hardworking and Drain vs. Asset scales was strong, $r=.77$ (see Section B3 of the Supplementary Materials for more on correlations). Therefore, we conducted a multivariate analysis of variance analysis (MANOVA) with the three types of intersections (two privileged categories, two marginalized categories, and mixed status category) entered as the independent variable and the scales entered as the dependent variables. Because individuals were given different intersecting sub-groups to rate, we could only make comparisons of ratings that aggregated types of groups (i.e., privileged, mixed, and marginalized), not particular groups (e.g., Arab male/female immigrant). Multivariate tests indicated a significant effect of the grouping variable on the two dependent variables, Pillai's trace $=.12, F(4,1422)=23.16, p<.001, \eta_{\mathrm{p}}^{2}=.06$. There was a statistically significant between-groups difference on both Vulnerable vs. Hardworking, $F(2,711)=35.61, p<.001, \eta_{\mathrm{p}}^{2}=.97$, and the Drain vs. Asset, $F(2,711)=47.78, p$ $<.001, \eta_{\mathrm{p}}^{2}=.98$, scales. We replicated the same effect when controlling for additional measures of threat indicator, and Fiske et al's (2002) warmth and competence dimensions (see Section B4 of the Supplementary Materials for additional covariance analysis). Table 2 shows the means for each group on each scale, denoting significant differences in the mean levels of both dependent variables between each of the privilege groupings. The means differed as we predicted: participants rated groups with two marginalized categories highest on Vulnerable and lowest on Assets (highest on Drain); they rated groups with two privileged categories as lowest on both Vulnerable and Drain; and ratings of mixed 
groups fell between these two on both dimensions. Further supporting the hypothesized distinctions, the means for each group differed significantly from each other on both scales.

Table 2

Mean Scores for Views of Groups With Different Privilege Statuses

\begin{tabular}{|c|c|c|c|c|c|c|}
\hline \multirow[b]{3}{*}{ Group view } & \multicolumn{6}{|c|}{ Privilege level of intersecting groups } \\
\hline & \multicolumn{2}{|c|}{ two marginalized } & \multicolumn{2}{|c|}{ mixed } & \multicolumn{2}{|c|}{ two privileged } \\
\hline & $M$ & $S D$ & $M$ & $S D$ & $M$ & $S D$ \\
\hline Vulnerable vs. Hardworking & $3.35 \mathrm{a}$ & 0.88 & $3.67_{\mathrm{b}}$ & 0.78 & $4.01_{\mathrm{c}}$ & 0.73 \\
\hline Drain vs. Asset & $3.25_{\mathrm{d}}$ & 0.77 & $3.54_{\mathrm{e}}$ & 0.70 & $3.93_{\mathrm{f}}$ & 0.63 \\
\hline$n$ & 270 & & 268 & & 176 & \\
\hline
\end{tabular}

Note. Means in each row with different subscripts are significantly different from each other. For Vulnerable vs. Hardworking, higher scores indicate higher perception of hard-working. For Drain vs. Asset, higher scores indicate higher perception of asset.

\section{Discussion}

Study 2 provided evidence that participants' responses to closed-ended survey items produced reliable scales, supporting their utility for research on stereotypes of immigrant groups. Although the two scales were highly correlated and produced parallel results in this analysis, as in Study 1 they provided distinctive information about particular groups. Moreover, although the dimensions were somewhat related in stereotypes of the immigrant intersections assessed in Study 1 (as suggested by the nearly empty quadrant in Figure 1), 10 of the 16 rated groupings in Study 2 reflected either two privileged or two marginalized social statuses. This likely inflated the relationship between these two scales in Study 2. Thus, we view the high correlation as a function of differences in the methods used in the two studies (the result of varimax rotation in Study 1 , where groups were defined by only one immigrant intersection, but highly correlated in Study 2 when there were two). For that reason, we see value in keeping the two scales separate.

Second, as we predicted based on intersectionality theory (Cole, 2009) and Study 1 findings, membership in two privileged categories was viewed significantly differently from membership in mixed categories, and both were different from membership in two marginalized categories. Those holding two privileged statuses were most often viewed as hardworking and assets to society, while those holding two marginal statuses were most often viewed as vulnerable and as drains to society; those with mixed statuses fell between these two.

\section{General Discussion}

Highlighting some of the key findings across our two studies, we emphasize the diversity of immigrant groups, the multidimensionality of immigrant stereotypes, and the value of using intersectionality as a framework for thinking about stereotype content. We situate the findings within the current debates about immigration in the United States and reflect on the value of an inductive approach for revealing shared and unique impressions of different groups with high (privileged) and low (marginalized) status social category memberships among immigrants.

\section{Intersectionality as a Framework for Studying Immigration}

Study 1 elicited stereotype content about immigrants who were further identified by an intersecting social category. This approach differs from that taken by most researchers who have looked at immigrant stereotypes in terms of predetermined dimensions (Fiske \& Lee, 2012; Zou \& Cheryan, 2017). Koch and colleagues (2016) identified three dimensions in their inductive study of many groups, but did not focus on intersecting immigrant groups. Thus, our study contributes to the literature with these inductively found stereotypes of immigrants and demonstrates the utility of an intersectional approach. 
Factor analysis yielded five dimensions, the first two of which we retained for further analysis and included themes familiar in popular immigration discourse. The first two factors (Vulnerable vs. Hardworking and Drain vs. Asset), which yielded the most reliable scales, provided fairly coherent impressions of immigrants. None of the scales clearly mapped onto existing formulations (e.g., Fiske et al., 2002); thus, though they included one or more terms from the Stereotype Content Model, they were distributed across the five scales. Items such as criminal and dangerous appeared in the second factor, suggesting elements of threat (Curşeu et al., 2007), but along with many items that did not.

Scales based on these two factors were then used to examine the profiles of four groups defined by legal definitions of immigrant status in the United States, as they differed from each other and as they compared with the profile of generic immigrant. These comparisons showed that documented immigrants were viewed in distinctively positive terms compared to the other groups. Refugees and asylum-seekers were viewed as equivalent, but different from undocumented immigrants, consistent with findings from Verkuyten et al. (2018).

Scale scores were examined across all 31 intersectional categories of immigrants. Results suggested that intersecting social group memberships associated with greater privilege were viewed as more hardworking and less likely to be drains on society, while group memberships associated with lower status and marginalization were considered likely to be national drains rather than assets, and varied in terms of being perceived as vulnerable vs. hardworking. All of these results confirm the value of generating content using multiple instantiations of immigrant status and of using the resulting content to study images of immigrants who are members of diverse and intersecting categories.

In Study 2 we tested the intersectional hypothesis that having two privileged group memberships would be associated with more positive stereotype content (hardworking and assets), while holding two marginalized group memberships would be associated with more negative content (vulnerable and drains). In addition, we predicted that holding mixed group status would place a group somewhat in between. These findings provided a direct test of the value of using intersectionality theory (e.g., Cole, 2009) in studying immigrant stereotypes, as they reflect a more complicated pattern of stereotypical beliefs.

\section{Immigrant Stereotypes Include a Mix of Positive and Negative Content}

By adopting a bottom-up approach to stereotype content for a large and diverse set of immigrant categories in both studies, we were able to obtain a broader and richer set of both positive and negative attributes than is usually reported in the literature on immigrant stereotypes. One particularly important finding, consistent with Guerra et al. (2015) and Verkuyten (2018), is that positive as well as negative beliefs about immigrant groups were reflected in the content of the stereotypes of these groups. Indeed, the single most frequently mentioned characteristic was hardworking, followed at some distance by smart, intelligent and friendly. The two primary factors, vulnerable vs. hardworking and drain vs. asset, included a mixture of positive and negative content. It is important to note that in both studies and consistent with intersectionality theory, the immigrant groups that were ascribed positive characteristics most often belonged to privileged social groups, marked by their ability to speak English, proximity to Whiteness, and/or higher occupational status.

\section{Immigrant Stereotype Content Reflects Concerns About Legal Status}

Results showed that views of immigrants are substantially shaped by information about their legal status (consistent with Verkuyten et al., 2018). Documentation, a prominent feature in U.S. immigration discourse, was important; participants considered documented immigrants to be more hardworking and less vulnerable, less likely to be a national drain, and generally more worthy. In contrast, they considered undocumented immigrants as more likely to be a national burden than any of the other legal status categories. It is important to note that the profile of an undocumented immigrant most closely resembled the generic immigrant, suggesting that this specific category may currently shape perceptions of all immigrants in the public mind. This is troubling since, in fact, only $23 \%$ of immigrants in the United States in 2017 were undocumented (Passel \& Cohn, 2019).

Refugees and asylum-seekers were also cast unfavorably as being a drain on national resources, although their vulnerability was acknowledged. These findings are similar to those recently reported by Verkuyten and colleagues 
(2018), who found that societal concerns about financial and social costs of immigration are more pronounced when immigration is involuntary- concerns that, in turn, predict lower support for immigration.

\section{The Role of Threat in Views of Immigrant Groups}

Consistent with previous research showing that anti-immigrant sentiment is stronger toward groups that are believed to threaten one's worldview or way of life (Hainmueller \& Hopkins, 2014; Stephan et al., 2005), our data show that immigrants who are seen as hardworking and as assets to society belong to groups that are most likely to be perceived as sharing a presumed "American" way of life and worldview. These groups are primarily - though not always - White, English-speaking, skilled, and documented. (We note that Irish and Polish immigrants, though currently considered White in U.S. racial-ethnic categorization, were not viewed as assets or as drains.) In contrast, groups characterized as both vulnerable and a drain on national resources include refugees, asylum-seekers, Syrians, non-English speakers, and unskilled workers. These findings are consistent with a recent review of predictors of anti-immigrant sentiment (Hainmueller \& Hopkins, 2014), research on the role of identity threat and zero-sum beliefs in anti-immigrant attitudes (Curşeu et al., 2007; Stephan et al., 2005), and research demonstrating that some immigrant groups are viewed as "indispensable" to the majority (Guerra et al., 2015). In light of this literature, our findings suggest that these two dimensions of stereotype content (i.e. vulnerable vs. hardworking and drain vs. asset) are important sources of positive and negative attitudes toward different immigrant groups in the United States. Changes in attitudes toward different immigrant groups may reflect changes in these two dimensions as well and may help explain how attitudes toward some immigrant groups (e.g., Irish and Polish) have become more positive over time.

Only a few studies have systematically examined changes in attitudes towards immigration and/or immigrants over extended periods of time (Coenders \& Scheepers, 1998; Meuleman, Davidov, \& Billiet, 2009; Wilkes, Guppy, \& Farris, 2008), and thus the conditions that might be most influential in altering immigrant stereotypes remain to be established.

\section{Strengths of the Current Studies and Utility of the Method}

We aimed to assess the utility of a qualitative, language-based approach to studying immigrant stereotypes. Although "top-down" approaches dominate research on images of immigrant groups and have their own strengths, we demonstrated the value of "bottom-up" approaches that situate groups within context (as did Koch et al., 2016). Many of the words and factors we obtained have not been routinely included in studies of immigrant stereotypes that presume the relevant dimensions. Moreover, factors obtained from a language-based approach provide greater specificity and help us understand features that underpin general assessments of positivity and negativity.

Additionally, despite some common elements, we identified differences from the more generic concept of immigrant, exemplified by the convergent and divergent patterns for immigrants of varying legal status. These comparisons depended on the ability to convert open-ended qualitative data into dimensional space provided by MEM. Our method of defining immigrant stereotype content answers Verkuyten's (2018) call for diverse approaches in social psychological studies of immigration.

\section{Limitations and Future Directions}

We recruited our samples from MTurk. Although skewed young, educated and left-leaning, MTurk samples produce results that are generally replicated in representative samples (Berinsky, Huber, \& Lenz, 2012; Krupnikov \& Levine, 2014), and generalize to broader U.S. samples.

We collected data during a particular period of immigration policy and public discourse in the United States, against a backdrop of a refugee ban, discussions of building a wall in the Southern border, and zero-tolerance policies. If policy and discourse play an important role in shaping the views of immigrants that the public holds, then it is important to conduct research that might help clarify the particular effects of particular policy and rhetoric. In an experimental paradigm, one might provide different accounts of immigrants as, for example, dangerous and demanding vs. law-abiding and hardworking, to determine whether different terms are attributed to the groups we studied based on their nationality, race, ethnicity, religion, gender, sexual orientation, professional and educational status. In addition, one 
could provide an account of a hypothetical country with, say, an "open-door" immigration policy, describe results of the policy as benign or alarming in terms of crime rate and economic productivity, and then evaluate the resulting views of immigrants. Alternatively, the MEM could be used to assess themes in documents, speeches, and media accounts of immigration. In this way, a comparison could be made between themes in the documents and themes that emerge when in survey respondents describe immigrant groups. Future research in contexts with different histories of immigration is also important, as is research on groups with different category intersections (e.g., groups from Africa, Asia, and Central and South America).

If immigrant stereotypes are malleable, as we suggest, the findings of this study may be limited to the particular country and time of our data collection, as well as the particular groups we included in our set of 31 immigrant groups. As an example, to limit respondent burden, we included only one set of presumably White immigrant group (Canadians) and only three presumably non-White national or ethnic groups (only Syrians, Arabs, and Mexicans). In addition, because different raters evaluated different groups in this study, we could not make direct comparisons of particular intersecting groups (e.g., English-speaking Canadians vs. English-speaking Arabs). We hope future research will remedy this limitation.

\section{Conclusion}

This study confirms that images of immigrants held by citizens in the receiving country are not homogeneous. Both contemporary context and historical circumstances affect the ways different immigrant groups are viewed. In the contemporary U.S. context, the generic 'immigrant' is not an image averaged across a range of immigrant features or represented by a specific feature or characteristic. Understanding how salient groups of immigrants fit into a larger picture is enhanced by analysis grounded in an intersectional framework that foregrounds the ways particular features can modify general images, therefore sharpens and deepens our understanding of how not all immigrants are alike in the public imagination.

Funding: The authors are grateful for support for data collection provided by the University of Michigan.

Competing Interests: The authors have declared that no competing interests exist.

Previously Presented: An earlier version of this article was presented at the symposium Immigrant representations in the United States: Capturing the heterogeneity held during the $13^{\text {th }}$ Annual Society for Psychological Study of Social Issues Convention in Pittsburgh, PA, June 2018.

Acknowledgments: The authors are grateful for assistance with MEM from James Pennebaker and Ryan Boyd, and for helpful feedback from our colleagues in the Gender and Personality in Context and Progress Lab research groups at the University of Michigan.

\section{Supplementary Materials}

The Supplemental Materials include additional information on sample characteristics, data cleaning procedures, and randomization both for Studies 1 and 2 and additional analyses for each study. In particular, for Study 1, the Supplemental Materials include the analysis of most frequent terms used describing immigrants and split-half analysis to assess the results of PCA on random subsamples. For Study 2, it includes descriptive statistics and correlations between the variables, as well as covariance analysis (for access see Index of Supplementary Materials below).

\section{Index of Supplementary Materials}

Savaş, Ö., Greenwood, R. M., Blankenship, B. T., Stewart, A. J., \& Deaux, K. (2021). Supplementary materials to "All immigrants are not alike: Intersectionality matters in views of immigrant groups" [Additional information and analyses]. PsychOpen.

https://doi.org/10.23668/psycharchives.4544 


\section{References}

Abdi, H., \& Williams, L. J. (2010). Principal component analysis. Wiley Interdisciplinary Reviews: Computational Statistics, $2,433-459$. https://doi.org/10.1002/wics.101

Alba, R., \& Foner, N. (2015). Strangers no more: Immigration and the challenges of integration in North America and Western Europe. Princeton, NJ, USA: Princeton University Press.

Berinsky, A. J., Huber, G. A., \& Lenz, G. S. (2012). Evaluating online labor markets for experimental research: Amazon.com's Mechanical Turk. Political Analysis, 20, 351-368. https://doi.org/10.1093/pan/mpr057

Bowleg, L. (2008). When black + lesbian + woman $\neq$ black lesbian woman: The methodological challenges of qualitative and quantitative intersectionality research. Sex Roles, 59, 312-325. https://doi.org/10.1007/s11199-008-9400-z

Boyd, R. L. (2017). Psychological text analysis in the digital humanities. In S. Hai-Jew (Ed.), Data analytics in digital humanities (pp. 161-189). https://doi.org/10.1007/978-3-319-54499-1_7

Boyd, R. L., \& Pennebaker, J. W. (2015). A way with words: Using language for psychological science in the modern era. In C. V. Dimofte, C. P. Haugtvedt, \& R. F. Yalch (Eds.), Consumer psychology in a social media world (pp. 222-236). New York, NY, USA: Routledge/Taylor \& Francis.

Ceobanu, A. M., \& Escandell, X. (2010). Comparative analyses of public attitudes toward immigrants and immigration using multinational survey data: A review of theories and research. Annual Review of Sociology, 36, 309-328. https://doi.org/10.1146/annurev.soc.012809.102651

Chung, C. K., \& Pennebaker, J. W. (2008). Revealing dimensions of thinking in open-ended self-descriptions: An automated meaning extraction method for natural language. Journal of Research in Personality, 42, 96-132. https://doi.org/10.1016/j.jrp.2007.04.006

Cisneros, J. D. (2015). A nation of immigrants and a nation of laws: Race, multiculturalism, and neoliberal exception in Barack Obama's immigration discourse. Communication, Culture \& Critique, 8, 356-375. https://doi.org/10.1111/cccr.12088

Coenders, M., \& Scheepers, P. (1998). Support for ethnic discrimination in the Netherlands 1979-1993: Effects of period, cohort, and individual characteristics. European Sociological Review, 14, 405-422. https://doi.org/10.1093/oxfordjournals.esr.a018247

Cole, E. R. (2009). Intersectionality and research in psychology. The American Psychologist, 64, 170-180. https://doi.org/10.1037/a0014564

Collins, P. H. (2015). Intersectionality's definitional dilemmas. Annual Review of Sociology, 41, 1-20. https://doi.org/10.1146/annurev-soc-073014-112142

Crenshaw, K. (1991). Mapping the margins: Intersectionality, identity politics, and violence against women of color. Stanford Law Review, 43, 1241-1299. https://doi.org/10.2307/1229039

Curşeu, P. L., Stoop, R., \& Schalk, R. (2007). Prejudice toward immigrant workers among Dutch employees: Integrated threat theory revisited. European fournal of Social Psychology, 37, 125-140. https://doi.org/10.1002/ejsp.331

Deaux, K. (2006). To be an immigrant. New York, NY, USA: Russell Sage Foundation.

Echabe, A. E., \& Castro, J. L. G. (1996). Images of immigrants: A study on the xenophobia and permeability of intergroup boundaries. European fournal of Social Psychology, 26, 341-352. https://doi.org/10.1002/(SICI)1099-0992(199605)26:3<341::AID-EJSP753>3.0.CO;2-4

Fiske, S. T., Cuddy, A. J., Glick, P., \& Xu, J. (2002). A model of (often mixed) stereotype content: Competence and warmth respectively follow from perceived status and competition. fournal of Personality and Social Psychology, 82, 878-902. https://doi.org/10.1037/0022-3514.82.6.878

Fiske, S. T., \& Lee, T. L. (2012). Xenophobia and how to fight it: Immigrants as the quintessential “other." In S. Wiley, G. Philogene, \& T. A. Revenson (Eds.), Social categories in everyday experience (pp. 151-163). https://doi.org/10.1037/13488-000

Guerra, R., Gaertner, S. L., António, R., \& Deegan, M. (2015). Do we need them? When immigrant communities are perceived as indispensable to national identity or functioning of the host society. European fournal of Social Psychology, 45, 868-879. https://doi.org/10.1002/ejsp.2153

Hainmueller, J., \& Hopkins, D. J. (2014). Public attitudes toward immigration. Annual Review of Political Science, 17, $225-249$. https://doi.org/10.1146/annurev-polisci-102512-194818

Hartman, T. K., Newman, B. J., \& Bell, C. S. (2014). Decoding prejudice toward Hispanics: Group cues and public reactions to threatening immigrant behavior. Political Behavior, 36, 143-163. https://doi.org/10.1007/s11109-013-9231-7 
Katz, D., \& Braly, K. (1933). Racial stereotypes of one hundred college students. fournal of Abnormal and Social Psychology, 28, $280-290$. https://doi.org/10.1037/h0074049

Koch, A., Imhoff, R., Dotsch, R., Unkelbach, C., \& Alves, H. (2016). The ABC of stereotypes about groups: Agency/socioeconomic success, conservative-progressive beliefs, and communion. Journal of Personality and Social Psychology, 110, 675-709. https://doi.org/10.1037/pspa0000046

Kotzur, P. F., Forsbach, N., \& Wagner, U. (2017). Choose your words wisely: Stereotypes, emotions, and action tendencies toward fled people as a function of the group label. Social Psychology, 48, 226-241. https://doi.org/10.1027/1864-9335/a000312

Krieger, N., Williams, D. R., \& Moss, N. E. (1997). Measuring social class in U.S. Public Health research: Concepts, methodologies, and guidelines. Annual Review of Public Health, 18, 341-378. https://doi.org/10.1146/annurev.publhealth.18.1.341

Krupnikov, Y., \& Levine, A. S. (2014). Cross-sample comparisons and external validity. fournal of Experimental Political Science, 1 , 59-80. https://doi.org/10.1017/xps.2014.7

Madon, S. (1997). What do people believe about gay males? A study of stereotype content and strength. Sex Roles, 37, 663-685. https://doi.org/10.1007/BF02936334

Meuleman, B., Davidov, E., \& Billiet, J. (2009). Changing attitudes toward immigration in Europe, 2002-2007: A dynamic group conflict theory approach. Social Science Research, 38, 352-365. https://doi.org/10.1016/j.ssresearch.2008.09.006

Mukherjee, S., Molina, L. E., \& Adams, G. (2012). National identity and immigration policy: Concern for legality or ethnocentric exclusion? Analyses of Social Issues and Public Policy, 12, 21-32. https://doi.org/10.1111/j.1530-2415.2011.01257.x

Murray, K. E., \& Marx, D. M. (2013). Attitudes toward unauthorized immigrants, authorized immigrants, and refugees. Cultural Diversity \& Ethnic Minority Psychology, 19, 332-341. https://doi.org/10.1037/a0030812

Ngai, M. (2004). Impossible subjects: Illegal immigrants and the making of modern America. Princeton, NJ, USA: Princeton University Press.

Niemann, Y. F., Jennings, L., Rozelle, R. M., Baxter, J. C., \& Sullivan, E. (1994). Use of free responses and cluster analysis to determine stereotypes of eight groups. Personality and Social Psychology Bulletin, 20, 379-390. https://doi.org/10.1177/0146167294204005

Niitsuma, H., \& Okada, T. (2005). Covariance and PCA for categorical variables. In T. B. Ho, D. Cheung, \& H. Liu (Eds.), PAKDD 2005: Advances in knowledge discovery and data mining. (Lecture Notes in Computer Science, Vol 3518, pp. 523-528). https://doi.org/10.1007/11430919_61

Ortner, S. B. (2003). New fersey Dreaming: Capital, culture and the class of '58. Durham, NC, USA: Duke University Press.

Passel, J. S., \& Cohn, D. (2019, June 12). Mexicans decline to less than half the U.S. unauthorized immigrant population for the first time. Pew Research Center. Retrieved from https://www.pewresearch.org/fact-tank/2019/06/12/us-unauthorized-immigrant-population-2017

Purdie-Vaughns, V., \& Eibach, R. P. (2008). Intersectional invisibility: The distinctive advantages and disadvantages of multiple subordinate-group identities. Sex Roles, 59, 377-391. https://doi.org/10.1007/s11199-008-9424-4

Ramírez-Esparza, N., Chung, C. K., Sierra-Otero, G., \& Pennebaker, J. W. (2012). Cross-cultural constructions of self-schemas: Americans and Mexicans. Journal of Cross-Cultural Psychology, 43, 233-250. https://doi.org/10.1177/0022022110385231

Rosenthal, L. (2016). Incorporating intersectionality into psychology: An opportunity to promote social justice and equity. The American Psychologist, 71, 474-485. https://doi.org/10.1037/a0040323

Schildkraut, D. J. (2011). Americanism in the twenty-first century: Public opinion in the age of immigration. New York, NY, USA: Cambridge University Press.

Settles, I. H. (2006). Use of an intersectional framework to understand Black women's racial and gender attitudes. Sex Roles, 22, 444-453. https://doi.org/10.1007/s11199-006-9029-8

Settles, I., \& Buchanan, N. (2014). Multiple groups, multiple identities, and intersectionality. In V. Benet-Martínez \& Y. Hong (Eds.), The Oxford handbook of multicultural identity. New York, NY, USA: Oxford University Press.

Stephan, W. G., Renfro, C. L., Esses, V. M., Stephan, C. W., \& Martin, T. (2005). The effects of feeling threatened on attitudes toward immigrants. International fournal of Intercultural Relations, 29, 1-19. https://doi.org/10.1016/j.ijintrel.2005.04.011

Timberlake, J. M., Howell, J., Baumann Grau, A. B., \& Williams, R. H. (2015). Who “They” are matters: Immigrant stereotypes and assessments of the impact of immigration. The Sociological Quarterly, 56, 267-299. https://doi.org/10.1111/tsq.12076

Timberlake, J. M., \& Williams, R. H. (2012). Stereotypes of U. S. immigrants from four global regions. Social Science Quarterly, 93, 867-890. https://doi.org/10.1111/j.1540-6237.2012.00860.x 
United Nations, Department of Economic and Social Affairs, Population Division. (2017). International Migration Report 2017: Highlights (ST/ESA/SER.A/404). Retrieved from

https:/www.un.org/en/development/desa/population/migration/publications/migrationreport/docs/ MigrationReport2017_Highlights.pdf

Verkuyten, M. (2018). The benefits of studying immigration for social psychology. European fournal of Social Psychology, 48, 225-239. https://doi.org/10.1002/ejsp.2354

Verkuyten, M., Altabatabaei, H. G., \& Nooitgedagt, W. (2018). Supporting the accommodation of voluntary and involuntary migrants: Humanitarian and host society considerations. Social Psychological \& Personality Science, 9, 267-274.

https://doi.org/10.1177/1948550617737600

Wilkes, R., Guppy, N., \& Farris, L. (2008). "No thanks, we're full”: Individual characteristics, national context, and changing attitudes toward immigration. International Migration Review, 42, 302-329. https://doi.org/10.1111/j.1747-7379.2008.00126.x

Zou, L. X., \& Cheryan, S. (2017). Two axes of subordination: A new model of racial position. fournal of Personality and Social Psychology, 112, 696-717. https://doi.org/10.1037/pspa0000080 